Ribeiro, E.M.; Machado, A.L.S.; Oliveira, E.C.; Nascimento, E.P. Monte Comunidades à margen da sustentabilidade: um olhar sobre o Polo Ecoturístico de Iranduba (AM). Revista Brasileira de Ecoturismo, São Paulo, v.5, n.1, jan/abr-2012, pp.11-26.

\title{
Comunidades à margem da sustentabilidade: um olhar sobre o Polo Ecoturístico de Iranduba (AM) ${ }^{1}$
}

\section{The communities in the margins of the sustainability: a look at the Iranduba Ecoturism Pole in Amazonas, Brazil}

\author{
Edinelza Macedo Ribeiro, Ana Lucia Soares Machado, \\ Elane Conceição de Oliveira, Elimar Pinheiro do Nascimento
}

\begin{abstract}
RESUMO
A Amazônia possui uma das maiores biodiversidade preservada do planeta. Dispõe de um banco genético precioso para a exploração científica e econômica, porém, encontra-se ameaçado pela degradação ambiental. Por apresentar uma rica sociodiversidade com grande número de etnias indígenas, marcada pela cultura dos povos ribeirinhos, rica em festas folclóricas, a região também é conhecida como Referencial do Ecoturismo. O presente artigo se propôs analisar o impacto do polo ecoturístico no município de Iranduba (AM) sobre as comunidades da região. A pesquisa é de natureza qualitativa, pois priorizou para a realização da coleta de dados a técnica metodológica do Grupo Focal. O que motivou a realização desse trabalho foi investigar o modus operandis do ecoturismo no Amazonas, com o fim de revelar se esta atividade tem sido realizada de acordo com o conceito defendido pela literatura. A escolha desse polo ecoturístico deu-se em virtude do município anteriormente citado abrigar a maior concentração de hotéis de selva e uma diversidade de comunidades ao seu redor. O resultado do estudo aponta que as comunidades naquele polo estão excluídas do processo que constitui o tripé do ecoturismo, tanto com relação ao equilíbrio ambiental, como o social e o econômico. Verifica-se também a falta de consenso dentro do mercado turístico local sobre a importância dos aspectos sociais e ambientais no setor. Com a realização desse estudo, espera-se contribuir com informações básicas da realidade do mercado ecoturístico do Estado do Amazonas para subsidiar construção de políticas públicas na região Norte do Brasil.
\end{abstract}

PALAVRAS-CHAVE: Ecoturismo; Sustentabilidade; Polo de Ecoturismo.

\begin{abstract}
The Amazon has one of the largest preserved biodiversity on the planet. It has a valuable gene bank for scientific and economic exploration, however, which is threatened by environmental degradation. Due to its rich social diversity with a large number of indigenous ethnicities, which is marked by the culture of peoples on the riverside and rich in folkloric festivities, the region is also known as a Reference in Ecotourism. This paper aims at analyzing the impact of the Iranduba (AM) ecotourism site on the local communities. Qualitative research using the Focal Group methodological technique was used for data collection. This work was carried out in order to investigate the modus operandi of ecotourism in the Amazon to show whether this activity is done in accordance with the concepts advocated in the literature. This ecotourism pole in Iranduba was chosen for its large concentration of jungle lodges and for the variety of its neighboring communities. The result of this study indicates that communities in this site are excluded from the process which is the ecotourism tripod, with respect to environmental, social and economic balance. There is also a lack of consensus within the local tourist market on the importance of social and environmental sector. This study aims to give a contribution with basic information of the reality of ecotourism market in the Amazonas state to subsidize the construction of public policies in the North region of Brazil.
\end{abstract}

KEYWORDS: Ecotourism, Sustainability, Ecotourism Pole. 


\section{Introdução}

Analisado como uma atividade econômica, o turismo é um fenômeno de demanda altamente associado ao consumo e seu desenvolvimento tem ocorrido em todas as regiões do país.

No estado do Amazonas, o cenário de desenvolvimento do turismo é promissor e aponta para o segmento de natureza, ligado ao lazer, o grande responsável pelo crescimento da demanda no local. Para a Empresa Estadual de Turismo - AMAZONASTUR (2009), 55,98\% dos visitantes que vêm ao Amazonas são motivados pelo turismo de lazer e, em sua grande maioria $(70,26 \%)$, proveniente do exterior.

Dentro dessa perspectiva, voltada ao desenvolvimento do turismo sustentável, a prática do ecoturismo se apresenta como uma das atividades que pode ser desenvolvida no Amazonas, já que atrativos naturais e culturais não faltam à região. $\mathrm{A}$ designação atribuída ao Estado como "Referencial Nacional do Ecoturismo" (RUSSO, 2005) justifica-se diante do potencial da biodiversidade e da sociodiversidade existente na região. E tem se mostrado uma importante alternativa para o desenvolvimento econômico local, como atividade menos impactante do que a mineração, a pecuária, a extração de madeira e a implantação de hidrelétricas.

Não é por acaso que esse segmento tem sido estratégico para o Amazonas, pois o Estado possui 14 Polos Ecoturísticos. A designação "Polo Ecoturístico" se refere a um conjunto de municípios que concentram muitos atrativos para a realização dessa prática (FERREIRA; COUTINHO, 2002). Assim, com exceção do município de Parintins (Polo Saterê), que é um destino indutor de desenvolvimento turístico, as cidades de Manaus, Presidente Figueiredo, Rio Preto da Eva, Iranduba, Manacapuru, Itacoatiara, Barcelos, Santa Isabel do Rio Negro, Altazes, Careiro, Careiro da Várzea, Silves, Novo Airão e São Gabriel da Cachoeira enquadram-se nos critérios e características de polos ecoturísticos (PLANO DE INCENTIVO AO TURISMO NA AMAZÔNIA, 2009).

Faria (2005) aponta alguns critérios que caracterizam esses polos: proximidade da capital, Manaus; potencial ecoturístico com produtos em operação; disposição de Unidades de Conservação; Reservas Ambientais e Áreas Indígenas. Critérios como infraestrutura mínima de acesso terrestre, fluvial e/ou aéreo e inserção destas áreas no Projeto Corredores Ecológicos ${ }^{2}$, também contribuem na escolha desses municípios como polos ecoturísticos.

Vale salientar que no contexto das definições existentes para o termo "ecoturismo", três características constituem o chamado tripé da sustentabilidade dessa atividade, a saber: garantia da conservação ambiental, educação ambiental e benefício às comunidades receptoras (FACO; NEIMAN, 2010). O termo sustentabilidade abordado nesta pesquisa, refere-se a concepção utilizada nas orientações básicas do Ecoturismo (2008) p.17, o qual: 
[...] visa promover a harmonia dos seres humanos entre si e com a natureza. Utilizar o patrimônio natural e cultural de forma sustentável representa a promoção de um turismo "ecologicamente suportável em longo prazo, economicamente viável, assim como ética e socialmente equitativo para as comunidades locais. Exige integração ao meio ambiente natural, cultural e humano, respeitando a fragilidade que caracteriza muitas destinações turísticas.

Desta forma, o maior desafio para os gestores dos Polos Ecoturísticos do Amazonas está em desenvolver políticas públicas voltadas para a utilização sustentável dos recursos naturais amazônicos, aliando conservação ambiental e bem-estar das populações que vivem nas comunidades localizadas nas áreas de influências dessas regiões - o que converge para um turismo em bases sustentáveis.

Para tanto, o objetivo deste trabalho foi analisar o impacto do polo ecoturístico de Iranduba/AM sobre as comunidades da região. $O$ que motivou a realização do mesmo foi investigar o modus operandis do ecoturismo no Amazonas com a pretensão de revelar se o ecoturismo que se desenvolve no Estado está de acordo com o conceito defendido pela literatura. A escolha desse polo deu-se em virtude do município de Iranduba abrigar a maior concentração de hotéis de selva do Amazonas e grande diversidade de comunidades ao seu redor.

Além dessa introdução, a seção imediata delineia os procedimentos metodológicos utilizados neste artigo, com a descrição do grupo focal e uma caracterização breve da área de estudo. A seção a seguir analisa e discute os resultados encontrados. Por fim, apresentam-se as considerações finais e sugestões.

\section{Procedimentos Metodológicos}

Para a realização de um diagnóstico do Polo Ecoturístico de Iranduba a metodologia que se adotou foi a seguinte:

a) Aplicação da técnica de Grupo Focal. Nesta dinâmica, priorizaram-se os seguintes atores sociais: seis representantes das comunidades locais e três representantes da gestão pública local.

b) Conhecer a área de estudo: localização e contexto histórico do Polo Ecoturístico de Iranduba, por meio de análise documental e pesquisa de campo.

\section{Instrumento de coleta de informações - Grupo Focal (GF)}

A técnica de coleta de dados Grupo Focal (GF) é aplicada em pesquisas qualitativas que foram muito usadas na área da psicologia (TRENTINI, 2000). Tem avança- 
do na pesquisa educacional (GOMES, 2005) e recentemente aplicada no ecoturismo conforme Neiman e Rabinovici (2008). A aplicação dessa técnica consiste na realização de uma conversa em grupo de pessoas, com um roteiro previamente elaborado. A condição para participar do grupo é demonstrar algum interesse comum para dar sua opinião, comentar sobre o tema, objeto da pesquisa, a partir de suas vivências. As conversas são mediadas por um facilitador do grupo.

O GF normalmente não deve exceder a 15 participantes. O grupo integrante desta pesquisa foi formado por representantes das associações comunitárias (São José, Alto de Nazaré, Caldeirão, Nossa Senhora do Perpétuo Socorro, São Pedro e Cacau Pereira), sendo três delas localizadas no entorno dos hotéis de selva e três comunidades situadas na sede do município, em um total de seis. Os representantes da gestão pública foram um turismólogo do Centro de Atendimento ao Turista (CAT), um componente da Secretaria Municipal de Turismo e um da Secretaria de Meio Ambiente.

O convite foi dirigido ao grupo citado anteriormente, com a finalidade de que contribuíssem de alguma forma para o avanço do turismo de base sustentável na região, sem receber qualquer espécie de gratificação. Todos os participantes inicialmente receberam informações sobre o tema da discussão.

As questões que subsidiaram o debate foram: atividades desenvolvidas pelos participantes, dinâmica econômica das comunidades e do município, benefícios e impactos das atividades turísticas para as comunidades locais, contribuição das comunidades para o desenvolvimento do ecoturismo, programas ou projetos ecoturísticos desenvolvidos pelo governo do estado e por empreendedores dos hotéis de selva e existência de etnias indígenas no entorno dos hotéis de selva. A mediadora do GF foi a professora da Universidade do Estado do Amazonas/UEA e doutoranda em Desenvolvimento Sustentável/UnB, neutra quanto às questões locais, pois não era conhecida do grupo. Esta conduziu a discussão de forma que os participantes pudessem opinar livremente sobre sua experiência ao longo dos anos na área de turismo e artesanato, com o cuidado para oportunizar a participação de todos.

\section{Caracterização e contextualização da área de estudo}

Iranduba, município do estado do Amazonas inclui-se na Região Metropolitana de Manaus, possui 40.735 habitantes, com 28.928 residindo na área urbana e 11.807 vivendo na zona rural (IBGE, 2010).

De acordo com o mapa de zoneamento do município, Iranduba possui 28 comunidades. Localiza-se a $27 \mathrm{~km}$ em linha reta da capital e $13 \mathrm{~km}$ via terrestre. Possui uma área de $2.215,0 \mathrm{Km}^{2}$. A cidade foi elevada à categoria de município pela Emenda Constitucional no 12, de 10 de dezembro de 1981, no Governo de José Bernardino Lindoso. Banhada pelo rio Negro e Solimões, limita-se com as cidades de Manaus, Novo Airão, Manacapuru, Careiro da Várzea e Manaquiri (Figura 1). 


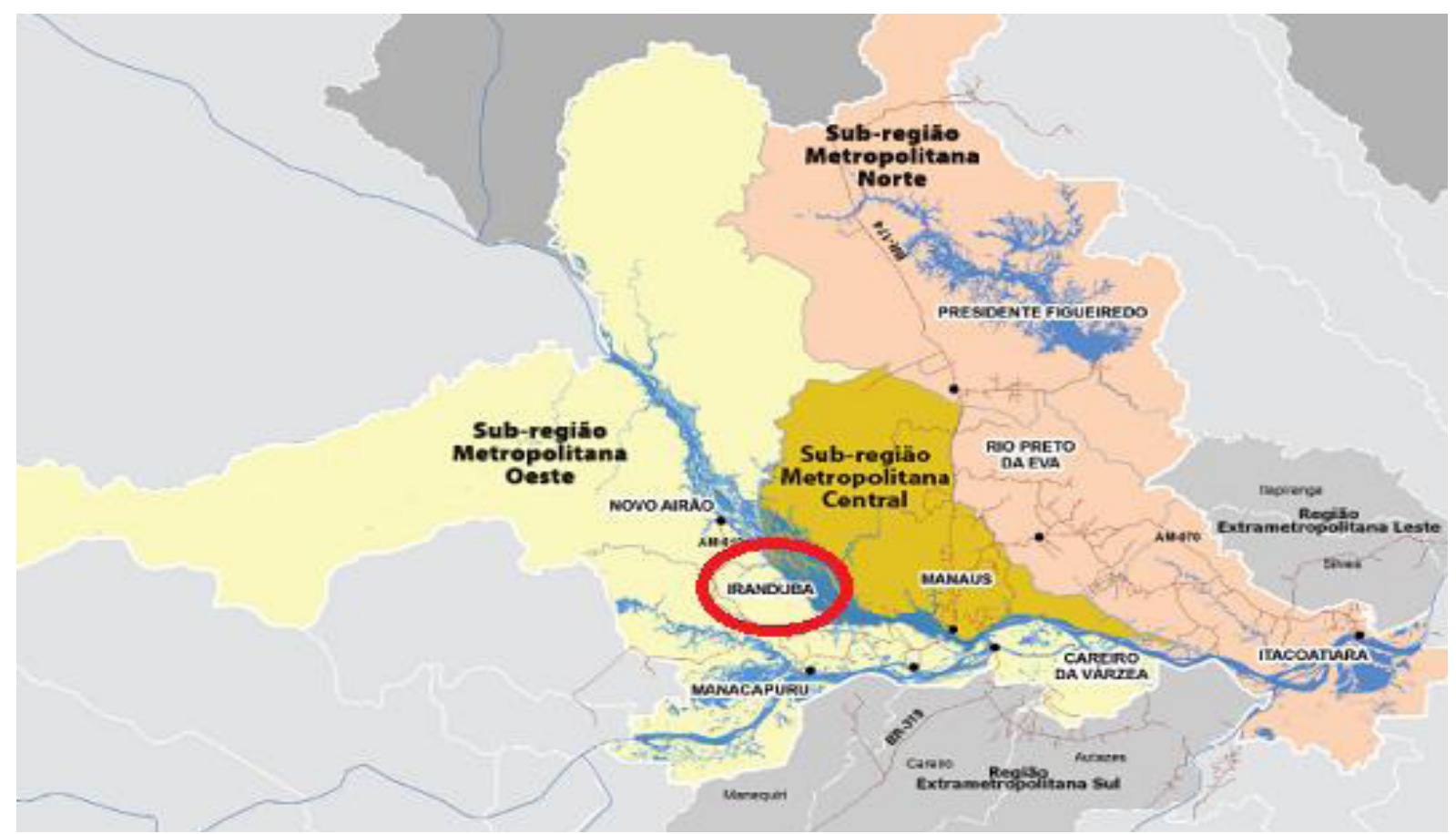

Figura 1: Localização do Município de Iranduba/AM - Região Metropolitana.

Fonte: Plano de Desenvolvimento Sustentável e Integrado da Região Metropolitana de Manaus, 2010.

A cidade de Iranduba se enquadra na categoria de Polo Ecoturístico por possuir a maior concentração de Hotéis de Selva: Ariaú Tower, Pousada Amazônia, Acajatuba, Tiwa Amazon Eco Resort, Amazon Fish, Pousada Ecológica, Hotel de Selva Lago Salvador, Tariri Amazon Lodge e outros. Além disso, a região faz parte do Corredor Ecológico': Projeto Corredor Central da Amazônia; possui duas Unidades de Conservação; detém logística favorável à capital do estado e uma riquíssima beleza cênica (Figura 2).

No âmbito da literatura brasileira sobre ecoturismo Neiman e Mendonça (2005); Lindberg e Hawkins (2005); contribuem com significativas publicações sobre o assunto. O Ecoturismo deve basear-se em uma perspectiva de sistemas que inclua a sustentabilidade e a participação da população rural local, naquelas regiões onde o maior potencial para o desenvolvimento de atividades ecoturísticas pode ser encontrado. Os eixos-chave dessa modalidade focaliza o desenvolvimento da comunidade local. Por desenvolvimento da comunidade local entende-se conferir poderes aos grupos locais para controlar e gerenciar reservas valiosas, por meio de mecanismos que se digam sustentáveis, mas que também satisfaçam as necessidades econômicas, sociais e culturais do grupo (HORWICH, et al., 2005). 


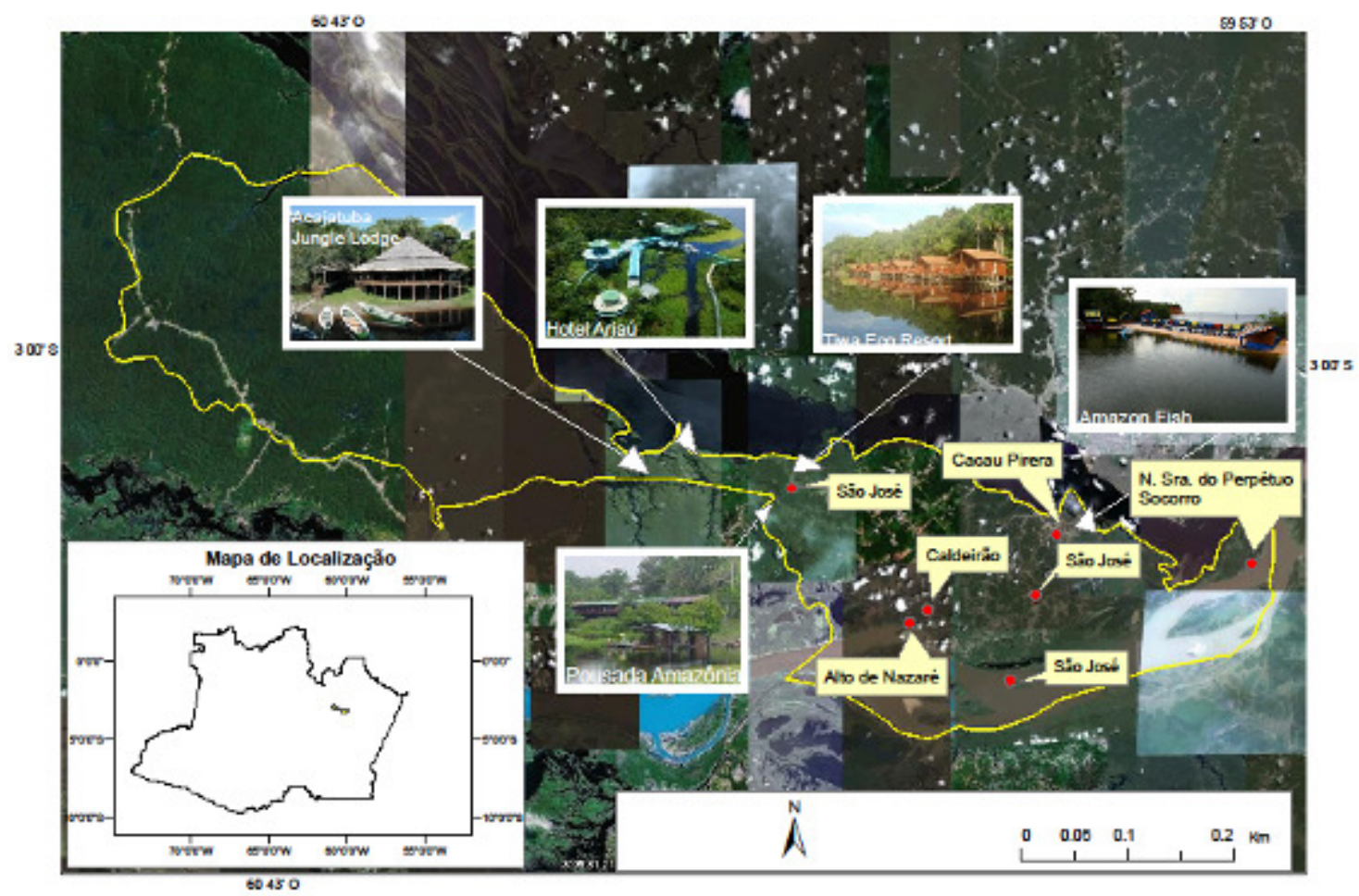

Figura 2: Mapa/localização das comunidades e Hotéis de Selva cidade Iranduba/AM.

Fonte: Criação Layout/Argemiro Neto/IBGE-2011.

\section{Resultados e Discussões}

De acordo com o conceito tratado neste artigo, o ecoturismo está fundamentado no tripé da sustentabilidade: equilíbrio ambiental, equilíbrio social e equilíbrio econômico. Os resultados desta pesquisa foram analisados dentro desta perspectiva:

\section{Equilíbrio Ambiental}

O turista que visita a região Amazônica é motivado pela beleza cênica e pelo imaginário popular da "Floresta Amazônica". No imaginário coletivo mundial, o Estado aqui em destaque surge como santuário ecológico e como "território índio" estando a cultura indígena imensamente associada ao produto Amazônia. Possuidor de uma rica biodiversidade distribuída em uma área de $1.570 .745 \mathrm{~km}^{2}$, o Estado conta ainda, com $98 \%$ de sua floresta original, distribuída em diversos Parques Nacionais e Reservas Biológicas. A presença da cultura indígena é marcante: o equivalente a 65 etnias vivem no Estado (AMAZONASTUR, 2009).

O município de Iranduba é o mais próximo da porta de entrada (Manaus) dos turistas de todo o mundo, porque apresenta uma concentração de atrativos naturais. Os comunitários confirmam em seus depoimentos a beleza e as potencialidades naturais do lugar, pois vivem em área privilegiada como: o encontro das águas, florestas preservadas, praias, vitória-régia, animais e espécies endêmicas da Bacia Amazônica 
como, por exemplo, o peixe pirarucu (Arapaina gigas).

Os empreendedores do Polo Ecoturístico de Iranduba, cientes desta beleza, usufruem da natureza e dos serviços ambientais gerados pela floresta tropical, os quais são: biodiversidade, beleza cênica, participação no ciclo hidrológico, sumidouro de gás carbônico, proteção do solo, fonte de alimentos e medicamentos (FEARSINDE, 1997; SALATI, 1983).

Após este estudo percebeu-se que há deficiência de dados sistematizados por parte desses empreendedores em conhecer a capacidade de carga ${ }^{3}$ para o uso sustentável dessas áreas, bem como os impactos provocados pela atividade ecoturística sobre os ecossistemas locais. Tanto que os representantes da Comunidade Nossa Senhora do Perpétuo Socorro, em suas falas, no GF revelaram, que na Vila de Cacau Pirêra, ocorre

[...] um tipo de ecoturismo só que não é basicamente desenvolvido dentro da comunidade, porque não recebem nenhum apoio do Hotel de Selva ali situado... [...] Ela diz também que na escola que trabalha diariamente os turistas vêm de todos os países visitarem a comunidade e as crianças têm o privilégio de estar junto com o turista e ela estava pensando em criar na comunidade a casa do caboclo, onde possam recepcionar os visitantes... [...] então a comunidade é linda e bem situada, mas precisa de recursos.

Os resultados apontam para os impactos ambientais, porém não quantificados nem qualificados, ou seja, os representantes comunitários convivem diariamente com muitos visitantes estrangeiros na área. Logo, nota-se que deve haver políticas públicas que integrem comunitários, gestores públicos do turismo, órgãos ambientais, a academia e os empreendedores dos hotéis de selva para que o desenvolvimento da atividade ecoturística no município seja sustentável.

No entanto, para garantir a manutenção da floresta e seus ecossistemas nessa região, medidas de proteção têm sido tomadas pela Secretaria de Desenvolvimento Sustentável do Amazonas (SDS) com relação à criação de Unidades de Conservação - UC's, tais como Área de Proteção Ambiental - APA da Margem Direita PaduariSolimões e Reserva de Desenvolvimento Sustentável - RDS Rio Negro e o Parque Ecológico do Lago Janauari. Porém, de acordo com as informações oriundas do GF, tais medidas ainda não são suficientes para a conservação e minimização dos impactos provocados pelo turismo de lazer. Pois as áreas continuam ocupadas por hotéis de selva, sem nenhum benefício aos moradores locais e controle pelos órgãos de fiscalização.

De acordo com Franco e Drummond (2009) mesmo com as políticas públicas da década de $1930^{4}$ e os avanços da pesquisa científica para a proteção da natureza o que prevaleceu nessas décadas foi o projeto político do desenvolvimentismo, que priorizava o crescimento econômico à custa da natureza. Todavia, os mesmos auto- 
res sugerem que a última década seja o tempo em que a natureza se torna objeto de políticas públicas mais efetivas.

Porém, não foi este o resultado encontrado pelos pesquisadores, o Estado vende uma imagem que não retrata a realidade das comunidades, a lógica econômica privada e competitiva ainda prevalece nesses locais. Diante disto, esta pesquisa revelou que a sustentabilidade ambiental no Polo Ecoturístico de Iranduba ainda é insipiente.

\section{Equilíbrio Social}

De acordo com Dale (2005) o conceito de ecoturismo ainda não apresenta uma definição precisa. Pires (2008) ao corroborar com esta idéia, afirma que a inexistência de um padrão consensual, leva vários setores a conceber sua própria idéia de ecoturismo em função dos seus próprios interesses. Isto foi verificado nas declarações dos moradores das comunidades rurais do município de Iranduba. Eles foram unânimes em afirmar que tanto o poder público municipal, estadual e federal, como as instituições ligadas diretamente na condução do fomento de políticas públicas do turismo no local, não reconhecem no ecoturismo uma alternativa de desenvolvimento sustentável para o local.

Com relação à oportunidade de emprego e renda, os envolvidos no GF reconheceram que não existe investimento na capacitação de mão de obra. Principalmente com relação às mulheres quando buscam vagas de camareiras e outras ocupações nos hotéis de selva. No que diz respeito às pessoas ligadas às atividades artesanais e proprietários de barracas de praias reconhecem que a falta de organização e qualificação dos serviços oferecidos contribui para o afastamento do turista do local.

Recursos como máquinas de costura para a confecção de roupas, sandálias de miçangas e a falta de clientela para comprar o artesanato foram algumas das contestações enfatizadas pelo grupo. Pelo que se pôde observar, dentre as seis comunidades participantes no GF, apenas a comunidade de Janauari está organizada em associação comunitária na exploração de artesanato. De acordo com seu presidente, essa estratégia vem apresentando resultados positivos, pois além de serem bem requisitados para participar de feiras em vários eventos, também conseguem viabilizar a divulgação e venda de seus produtos.

[...] somos privilegiados temos uma feira de artesanato lá no parque ecológico com uma associação com cerca de 29 associados que dispõem e vendem seus produtos. E hoje eu estou na condição de presidente dos produtores da comunidade São Pedro que representa a renda per capita de $60 \%$ da comunidade, outros vivem da pesca, agricultura e do comercio. Então Janauarí é privilegiada sim, a gente tá nessa qualidade. A associação é nova temos apenas oito meses estamos legalizando os documentos da associação e temos um evento que promovemos com o intuito de divulgar o artesanato e a gente tai pra ajudar da melhor forma. 
Entretanto, reclamou sobre a diminuição de fluxo turístico e baixa venda de artesanato, em que:

\begin{abstract}
[...] de uns tempos pra cá deu uma decaída muito grande por problemas internos nos transatlânticos. Janauari vendia muito artesanato mesmo. Hoje tem novas sementes, pena, madeira... [...] não pode mais entrar nos navios, ou seja, turistas do transatlântico não podem mais comprar esse tipo de material... [...]... Os turistas que levam esse tipo de material geralmente são os turistas que vêm de navio e volta de avião... [...] até por causa de questões alfandegárias. Então a gente tem esse probleminha, mas assim é um problema que teria que ser resolvido lá porque muito se falava que a semente criava um fungo e isso causava alergias.
\end{abstract}

Ao refletirem sobre $o$ isolamento e falta de oportunidade diante das atividades ecoturísticas, alguns membros desejosos na mudança desse quadro falaram na criação da "casa do caboclo", cujo objetivo seria o de recepcionar os turistas. Nesse contexto observou-se que esse "isolamento" iria ser superado em decorrência da inauguração da Ponte Rio Negro que liga Manaus a Iranduba. O que de certa forma pode favorecer maior fluxo turístico, como também integrar a Região Metropolitana de Manaus (RMM) e favorecer o escoamento da produção do pequeno e médio produtor rural.

Outros fatores de conflitos constatados são, por exemplo: falta de título definitivo da terra, ausência e incoerência de políticas públicas, contradição entre manejo, conservação e desenvolvimento econômico. A falta de estímulo dos comunitários na viabilidade econômica turística também foi foco de discussão dos participantes. Diante deste conjunto de fatores, um turismólogo representante do (CAT) disse que "é muita falação e não vê ninguém fazer nada de concreto". E afirma que "o município é deixado de lado e que os projetos de ecoturismo para o local têm que sair do papel e não ficar só na conversa".

Segundo os representantes das comunidades do entorno dos Hotéis de Selva existem conflitos entre grupos de indígenas e as comunidades tradicionais do local. Esse fato se originou devido ao empreendedor se valer do marketing cultura indígena associada ao produto Amazônia trazendo grupos indígenas exógenos para áreas que já eram habitadas pelas comunidades tradicionais.

Essa situação contrasta com os eixos-chave dos pressupostos do ecoturismo, quando defendem o desenvolvimento da comunidade local. Por desenvolvimento da comunidade local, entende-se conferir poderes aos grupos locais para controlar e gerenciar reservas valiosas, por meio de mecanismos que se digam sustentáveis, mas que também satisfaçam as necessidades econômicas, sociais e culturais do grupo (HORWICH, et al., 2005).

É nesse fio condutor de análise que Jones (2005) cita Campbell (1999); Colvin (1996); Loon e Palakow (2000) por questionarem em seus estudos se as comunida- 
des locais se beneficiam da indústria do ecoturismo. Uma empresa que explora esse tipo de atividade só pode ser considerada de "sucesso", se as comunidades locais usufruírem, de alguma forma, do controle desses benefícios, principalmente da participação equitativa. Essa preocupação existe pelo fato de que grande parte desse controle é quase totalmente feito por operadoras turísticas localizadas fora do local de origem do empreendimento (SCHEVYNS, 1999).

\section{Equilíbrio Econômico}

Em função da grande concentração econômica existente na capital amazonense proveniente da indústria de transformação do Polo Industrial de Manaus - PIM, o PIB do município de Iranduba representa apenas $0,36 \%$ do PIB do Estado, a preços correntes de 2008 (IBGE, 2011). Sendo distribuído em termos de valor adicionado: agropecuária $23,31 \%$, indústria $13,09 \%$, serviços $58,50 \%$ e Imposto $5,10 \%$.

Apesar dos serviços deterem um pouco mais da metade da riqueza municipal, a participação da administração pública no PIB é uma tendência dos municípios brasileiros, Iranduba possui dois potenciais econômicos: indústria de transformação (polo oleiro) e o turismo de natureza (polo ecoturismo).

O primeiro é sinalizado pelo Plano Diretor da Região Metropolitana de Manaus PDRMM (2010), revelando, inclusive, que um polo oleiro é a única atividade que apresenta viabilidade econômica para o desenvolvimento do município. No entanto, esta pesquisa revelou que, apesar da potencialidade, uma preocupação que surge é o grande consumo de lenha como insumo para produção de telhas e tijolos. Dados do Instituto Nacional de Pesquisas Espaciais/Monitoramento do desmatamento da Amazônia por Satélite INPE/PRODES (2011) revelam que o desmatamento em Iranduba passou de $336,2 \mathrm{~km}^{2}$ em 2000 para 465,2 $\mathrm{km}^{2}$ em 2009, representando um crescimento de $38,37 \%$ em quase uma década. Além disso, em 2011 o desmatamento já representa $20,87 \%$ da área territorial do município. Há necessidade de agregar maior sustentabilidade a essa atividade para que as florestas não sejam prejudicadas. É o que revelam os comunitários.

O segundo é sinalizado pelas comunidades locais, que afirmaram no GF ser o ecoturismo a grande vocação da região, $a b$ integro ${ }^{5}$.

[...] Iranduba tem aqui dentro da orla cinco a sete hotéis, que têm uma demanda muito grande de fluxo e muitas pessoas da região, mas às vezes desconhecem que a atividade do turismo é diferente do ecoturismo. Ecoturismo se baseia em trazer uma questão que devolva o potencial econômico da região ou equilíbrio econômico para aquele local que gerem pessoas que mobilizem aquele local, que vá buscar um determinado entendimento do seu local para atingir um resultado positivo que dê um suporte maior para aquela comunidade com a questão econômica, mão de obras e outras questões para desenvolver esse polo. 
O ecoturismo praticado de acordo com o pensamento dos comunitários constitui-se uma atividade altamente sustentável do ponto de vista econômico, social e ambiental, por se preocupar com a conservação ambiental e o bem-estar social.

Não é de hoje que ecoturismo tem sido praticado em Iranduba. No entanto, a pesquisa revelou que não há uma divisão justa de benefícios. A agregação de valor da atividade é a mínima possível para as comunidades que vivem no entorno dos hotéis de selva:

-Não há fornecimento de alimentos por parte das comunidades, como: frutas e pequenos animais (frango, peixe, etc.), porque não existe incentivo para desenvolver uma agropecuária familiar. Os alimentos vêm de Manaus;

-As pessoas contratadas para trabalhar nos hotéis do lugar geralmente são da capital, porque possuem maior qualificação profissional, como curso de inglês, informática, entre outros;

-Não existe nenhum tipo de fundo financeiro levantado pelos hotéis para compensar o uso dos recursos naturais de Iranduba, ou para que as comunidades locais possam desenvolver alguma atividade econômica com o fim de suprir suas necessidades básicas.

Se não bastasse, o Polo Ecoturístico de Iranduba não tem impactado positivamente as atividades características do turismo da região. $\mathrm{O}$ crescimento dos serviços de alimentação e alojamento, por exemplo, esteve praticamente estagnado ao longo do tempo. Passou de 7 pessoas ocupadas em 2006 para 7 pessoas em 2009, representando $0,0 \%$. Fato este altamente desproporcional em relação ao Amazonas, que cresceu $17,01 \%$ no mesmo período (Figura 3).

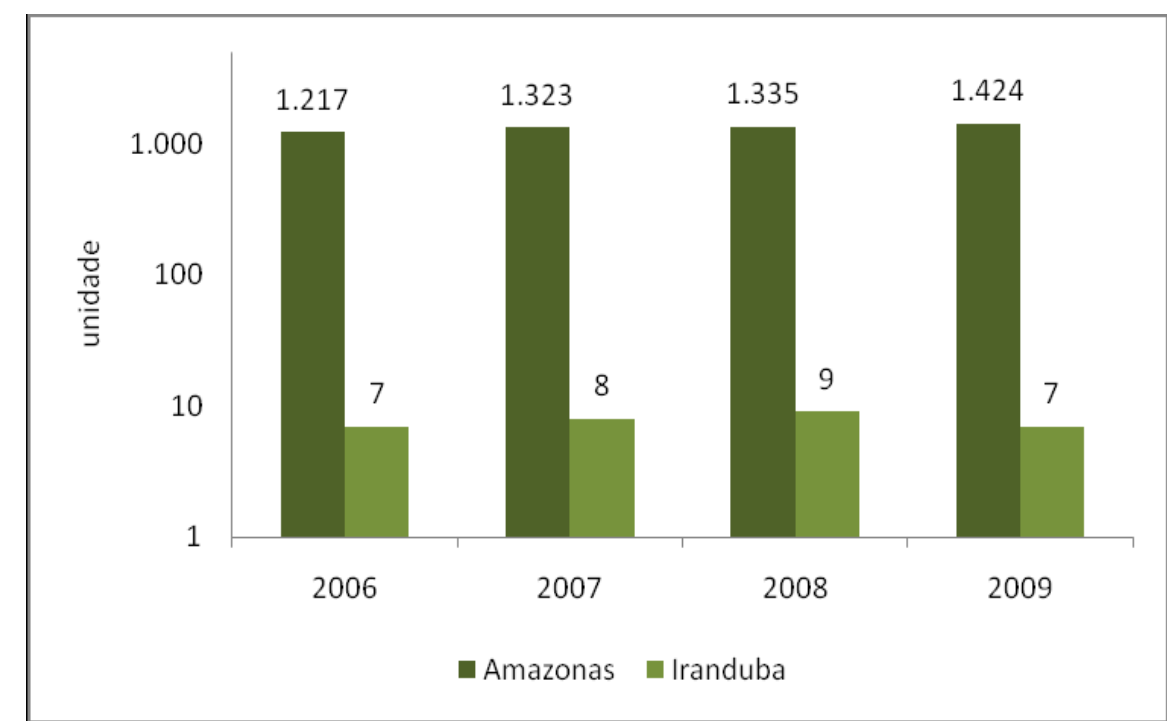

Figura 3: Atividade com alojamento e alimentação no Amazonas e no Município de Iranduba/AM. Fonte: IBGE - Cadastro Central de Empresas. 
Isto certamente demonstra que a geração de emprego e renda na região decorre minimamente da atividade ecoturística. Essas constatações só revelam que o modus operandis do turismo de natureza que tem sido praticado no interior do Estado contribui para que as comunidades fiquem à margem da sustentabilidade.

\section{Considerações Finais}

A proposta deste estudo foi analisar o impacto do polo ecoturístico no município de Iranduba-AM sobre as comunidades da região. Após sua conclusão, observouse que o resultado aponta para a exclusão das mesmas, ou seja, estão à margem da sustentabilidade, principalmente quando analisadas no tripé base-eixo constitutivo do ecoturismo, tanto no equilíbrio ambiental, como no social e econômico. Verificou-se que é muito acentuada a falta de consenso dentro do mercado turístico sobre a importância dos aspectos sociais e ambientais no setor.

Considerando os aspectos do ecoturismo priorizados no tripé da sustentabilidade, concluiu-se que, com relação aos resultados das questões ambientais, planejar a gestão do ecoturismo em áreas naturais representa atualmente um dos maiores desafios. Esse fato tem gerado conflitos de interesses, já que compatibilizar políticas que elaborem projetos ecoturísticos no Amazonas, num cenário ainda indefinido e dividido entre a perspectiva de ocupação da área, pelos modelos tradicionais de uso, ocupação do solo e preservação de áreas florestais de elevado potencial em biodiversidade, tem inflamado várias discussões.

Somando-se a isso, a inexistência de estudos por parte dos empreendedores do mercado do turismo na região, quanto a capacidade de carga e sustentabilidade ambiental, coloca em risco o equilíbrio desse ecossistema. Mesmo existindo medidas de proteção direcionadas às Unidades de Conservação existente no local, essas não são suficientes para que se minimizem os impactos decorrentes dos empreendimentos.

No que se refere aos resultados sociais, verificou-se a falta de apoio dos governos municipal, estadual e federal com relação à efetividade na implementação de projetos turísticos para a comunidade local. Além da sede do município não interagir com a mobilidade turística presente nos hotéis de selva, a ausência da capacitação de mão de obra, bem como o fomento de políticas públicas adequadas à cultura e estímulo à criação de associações como mecanismo no fortalecimento sustentável para as comunidades, são visíveis. Um dos pontos observados foi o comportamento dissimulado de alguns empreendedores de hotéis de selva, quando alegaram que apresentam muitos atrativos da cultura indígena para os turistas. Tais fatores inclusive vêm gerando conflitos entre algumas comunidades no entorno dos hotéis de selva.

Quanto aos resultados da análise econômica, constatou-se que, dentre as atividades geradoras de renda, a agropecuária, indústria e os serviços, o potencial da região como atrativo ecoturístico, é a alternativa mais viável e menos impactante como fonte geradora de emprego e renda. Entretanto, o que está claro no estudo é que não existe uma divisão justa desses benefícios no local, nem tampouco um parâmetro es- 
tatístico apontando que os 58,50\% mobilizados na dinâmica econômica dos serviços sejam relacionados às atividades do ecoturismo. A falta de valores agregados aos produtos contribui ainda mais, para deixar as comunidades à margem da sustentabilidade na região.

Enfim, acredita-se que esse estudo possa contribuir para a sensibilização e reflexão sobre o real sentido dos pressupostos do ecoturismo e seu compromisso focado no desenvolvimento das comunidades. Caso contrário, os conceitos, os fins e os meios do benefício dessa prática serão sempre pensados e classificados sob a ótica e influência de diferentes grupos de interesses e contextos socioeconômicos, culturais e ambientais, totalmente desambientados da cultura amazônica.

\section{Referências Bibliográficas}

AYRES, J.M.; FONSECA, G.A.B.; RYLANDS, A.B. ; QUEIROZ, H.L.; PINTO, L.P.S. ; MASTERSON, D.; CAVALCANTI, R.B. Os corredores ecológicos das florestas tropicais do Brasil. Belém, PA: Sociedade Civil Mamirauá, p.256, 2005.

BRASIL. Decreto $N^{0}$. 23793. Aprova o Código Florestal. Diário Oficial da República Federativa do Brasil, Rio de Janeiro, p. 25.538, 23 jan. 1934a.

BRASIL. Ministério do Turismo. Ecoturismo: orientações básicas. / Ministério do Turismo, Secretaria Nacional de Políticas de Turismo, Departamento de Estruturação, Articulação e Ordenamento Turístico, Coordenação Geral de Segmentação. - Brasília: Ministério do Turismo, p. 17, 2008.

DALE, P. Definindo ecoturismo... Para quê? Para quem? In: MENDONÇA, R.; NEIMAN, Z. (Orgs.). Ecoturismo no Brasil. Barueri, SP: Manole, 2005.

CIFUENTES, M. Determinacion de capacidad de carga turística em áreas protegidas. CATIE, Turrialba, Costa Rica, 1992.

EMPRESA ESTADUAL DO ESTADO DO AMAZONAS - AMAZONASTUR. Síntese dos indicadores do turismo 2003-2009.

FACO, R.A; NEIMAN, Z. A natureza do ecoturismo: conceitos e segmentação. In: NEIMAN, Z.; RABINOVICI, A. (Orgs.). Turismo e Meio Ambiente no Brasil. Barueri, SP: Manole, 2010.

FARIA, I.F. Ecoturismo: etnodesenvolvimento e inclusão no Amazonas. Passos. Revista de Turismo y Patrimônio Cultural, v.3 n.1, 2005, pp. 63-77.

FEARNSIDE, P.M. Protection of mahogany: A catalytic species in the destruction of rain forests in the American tropics. Environmental Conservation. v.24, n.4, 1997, pp. 303-306.

FERREIRA, F; COUTINHO, M. C. B. Ecoturismo: visitar para conservar e desenvolver a Amazônia. Brasília: MMM/SCA/Proecotur, 2002. 
FRANCO, J.L.A.; DRUMMOND, J.A. Proteção à natureza e identidade nacional no Brasil, anos 1920-1940. Rio de Janeiro, RJ: Editora FIOCRUZ, 2009.

GOMES, S.R. Grupo Focal: uma alternativa em construção na pesquisa educacional. Cadernos de pós-graduação, São Paulo, v.4, 2005, pp. 39-45.

HORWICH, R.H. MURRAY, D.; SAQUI, E. ; LYON, J.; GODFREY, D. O Ecoturismo e o desenvolvimento da comunidade: a experiência de Belize. In: LINDBERG, K.; HAWKINS, D.E (Orgs.) Ecoturismo: um guia para planejamento e gestão. $5^{\underline{a}}$ ed. São Paulo: Editora Senac. 2005, pp, 257-284.

INSTITUTO BRASILEIRO DE GEOGRAFIA E ESTATÍ́STICA - IBGE. PIB Municipal. Disponível em: <http://www.ibge.gov.br/home/estatistica/economia/ pibmunicipios/2004 2010/defaulttab.shtm>, Acesso em: 15/06/2011.

INSTITUTO BRASILEIRO DE GEOGRAFIA E ESTATÍSTICA - IBGE. Cadastro Central de Empresas. .Disponível em: <http://www.ibge.gov.br/home/estatistica/ economia/cadastroempresa/2009/default.shtm>, Acesso em: 15/06/2011.

INSTITUTO NACIONAL DE PESQUISAS ESPACIAIS - INPE. Projeto PRODES: Monitoramento da Floresta Amazônica Brasileira por Satélite. Disponível em: <http:// www.dpi.inpe.br/prodesdigital/prodesmunicipal.php>, Acesso em: 10/06/2011.

JONES, S. Community-Based Ecotourism: The significance of social capital. Annals of Tourism Research, Northumbria University, UK, v.32, n.2, 2005, pp. 303-324.

LINDBERG, K.; HAWKINS. D.E. (Orgs.). Ecoturismo: um guia para planejamento e gestão. 5 ed. São Paulo: Editora Senac, 2005.

NEIMAN, Z.; RABINOVICl, A. A Educação Ambiental através do Ecoturismo: o diferencial das atividades de contato dirigido com a natureza. Revista Pesquisa em Educação Ambiental, v.3, n.2, 2008, pp. 77-101.

NEIMAN, Z.; MENDONÇA, R. (Orgs.). Ecoturismo no Brasil. Barueri, SP: Manole, 2005.

PIRES, P.S. Dimensões do ecoturismo. São Paulo: Editora Senac, 2008.

PLANO DE DESENVOLVIMENTO SUSTENTÁVEL E INTEGRADO DA REGIÃO METROPOLITANA DE MANAUS - PDRMM, Ed. 2. Secretaria da Região Metropolitana de Manaus. René Levy Aguiar, Consórcio Vetec/Valente, 2010.

PLANO DE INCENTIVO AO TURISMO NA AMAZÔNIA, BANCO DA AMAZÔNIA, 2009.

PRODES-INPE. . Desmatamento dos Municípios. Disponível em: http:// www.dpi.inpe.br/prodesdigital/prodesmunicipal.php, Acesso em: 15/06/2011.

PROGRAMA PARA O DESENVOLVIMENTO DO ECOTURISMO NA AMAZÔNIA LEGAL BRASILEIRA - PROECOTUR, 2003. Disponível em: http://www.mma.gov.br/pot/ sca/proeco/turverd.html, Acesso em: 26/08/2009. 
RUSSO, C.R. Comunidades Tradicionais e preservação cultural por meio do ecoturismo. In: MENDONÇA, R.; NEIMAN, Z. (Orgs). Ecoturismo no Brasil. Barueri, SP: Manole, 2005.

SALATI, E. O clima atual depende da floresta. As águas da região amazônicas. In: SALATI, E., JUNK, W.J.; SHUBART, H.O.R.; OLIVEIRA, A.E. (org.) Amazônia: desenvolvimento, integração e ecologia. São Paulo: Brasiliense/Brasília/CNPq, 1983 pp. 15-44.

SCHEVYNS, R. Ecotourism and the Empowerment of Local Communities. Tourism Management, v.20, 1999, pp.245-249.

TRENTINI, M.; GONÇALVES, L. H. T. Pequenos grupos de convergência: um método no desenvolvimento de tecnologias na enfermagem. Texto e Contexto em Enfermagem, Florianópolis (SC), v. 9, n. 1, 2000, pp.63-78.

\section{Notas}

${ }^{1}$ Os dados parciais fazem parte da coleta de dados da tese de doutoramento e foram apresentados no Workshop "Ecoturismo e Cenário: estratégias de desenvolvimento para o Amazonas", realizado no período de 19 a 21 de julho de 2011, na cidade de Manaus (AM), como também estão publicados nos anais do IX Encontro da Sociedade Brasileira de Economia Ecológica, realizado em Brasília (DF), entre os dias 04 e 08 de outubro de 2011.

${ }^{2}$ Corredores Ecológicos são as grandes extensões de ecossistemas florestais biologicamente prioritárias na Amazônia e na Mata Atlântica, delimitados em grande parte por conjuntos de unidades de conservação (existentes ou propostas) e pelas comunidades ecológicas que contém. Ayres (2005).

${ }^{3}$ Capacidade de carga é um conceito usado desde 1983, no campo do Ecoturismo para fixar limites, ordenar e manejar a visitação em áreas naturais. Pode ser definida como o limite máximo de resistência do local com base nos fatores de resistência ambiental e a capacidade de assimilar os impactos provenientes dessas atividades (CIFUENTES, 1992).

${ }^{4}$ Código Florestal Brasileiro instituído em 1934, Código Florestal Brasileiro (Decreto $n^{\circ}$ 23.793, de 23-01-1934).

${ }^{5} a b$ integro: fielmente, não alterado.

\section{Agradecimentos}

Em especial, à Fundação de Amparo à Pesquisa do Estado do Amazonas - FAPEAM. que viabilizou total apoio na realização desta pesquisa, a qual contribuiu para retratar os resultados parciais da realidade do Ecoturismo no Estado do Amazonas; 
às colegas do curso de doutorado, pelo apoio na coleta de dados: aos representantes das Comunidades de Iranduba envolvidos na pesquisa e os representantes da Secretaria Municipal de Turismo local.

Edinelza Macedo Ribeiro: Universidade do Estado do Amazonas, Manaus, AM, Brasil. Email: ediribeiro27@hotmail.com Link para o currículo Lattes: http://lattes.cnpq.br/5385395813417606

Ana Lucia Soares Machado: Universidade de Brasília - Centro de Desenvolvimento Sustentável CDS, Brasília, DF, Brasil.

Email: analusmachado@hotmail.com

Link para o currículo Lattes: http://lattes.cnpq.br/8651168588446017

Elane Conceição de Oliveira: Universidade de Brasília - Centro de Desenvolvimento Sustentável CDS, Brasília, DF, Brasil.

Email: ecoliveira_eco@hotmail.com

Link para o currículo Lattes: http://lattes.cnpq.br/9219459569460852

Elimar Pinheiro do Nascimento: Universidade de Brasília - Centro de Desenvolvimento Sustentável CDS, Brasília, DF, Brasil.

Email: elimarcds@gmail.com

Link para o currículo Lattes: http://lattes.cnpq.br/5290901839648752

Data de submissão: 31 de agosto de 2011

Data de recebimento de correções: 10 de dezembro de 2011

Data do aceite: 10 de dezembro de 2011

Avaliado anonimamente 